\title{
Diagnostic dilemma in extra-pulmonary tuberculosis: PCR a convenient tool
}

\author{
Ratna Shukla $^{1, *}$, Anil Kumar Bilolikar ${ }^{1}$ and Sukrutha Gopal Reddy ${ }^{1}$ \\ ${ }^{1}$ Department of Microbiology, Krishna Institute of Medical Sciences, Minister Road, Secunderabad-500003, Telangana, India
}

\begin{abstract}
Background: Mycobacterium tuberculosis infection usually manifests as pulmonary tuberculosis and rarely as extra-pulmonary tuberculosis (EPTB). In recent past, there is an increase in the cases of extra-pulmonary tuberculosis. The diagnostic difficulty owing to paucibacillary nature of EPTB poses a challenge in diagnosis and consequently treatment. In this scenario, Polymerase chain reaction (PCR) serves as a convenient tool which gives results within a short time along with other conventional methods in the diagnosis of extra-pulmonary tuberculosis.
\end{abstract}

Aims: To detect Mycobacterium tuberculosis complex (MTBC) by DNA PCR in clinically suspected cases of EPTB.

Materials and methods: Clinical samples from suspected cases of EPTB were collected and processed according to the standard guidelines. Smears prepared were subjected to Ziehl-Neelsen (ZN) staining. Nested PCR was performed on extracted DNA from homogenized samples using commercial kit with MTB target gene of IS6110.

Results: A total of 156 samples were received for molecular diagnosis of EPTB over a year. They were all subjected to ZN staining and PCR test. All 156 samples were negative for AFB by ZN staining. Out of total 156 samples, $8(5.12 \%)$ samples were detected positive by MTB-DNA PCR test. The most common site of EPTB found in this study was pleura (14.28\%). Other sites included genito-urinary tract (13.33\%), CNS (4.65\%) and endometrium (3.44\%).

Conclusion: Early diagnosis and treatment of EPTB reduces complications and morbidity in affected patients. Though PCR is expensive; in diagnostic dilemma in suspected cases of EPTB, it can be included in diagnostic panel to clinch the diagnosis early and start pre-emptive treatment.

Keywords: Extra-pulmonary tuberculosis; MTB DNA-PCR; ZN staining; MTBC

\begin{abstract}
*Corresponding author: Dr. Ratna Shukla, Department of Microbiology, Krishna Institute of Medical Sciences, Minister Road, Secunderabad-500003, Telangana, India. Email: ratnashukla8@ gmail.com
\end{abstract}

Received 17 July 2018; Revised 31 August 2018; Accepted 10 September 2018; Published 18 September 2018

Citation: Shukla R, Bilolikar AK, Reddy SG. Diagnostic dilemma in extra-pulmonary tuberculosis: PCR a convenient tool. J Med
Sci Res. 2018; 6(4): 97-102. DOI: http://dx.doi.org/10.17727/ JMSR.2018/6-17

Copyright: (c) 2018 Shukla R et al. Published by KIMS Foundation and Research Center. This is an open-access article distributed under the terms of the Creative Commons Attribution License, which permits unrestricted use, distribution, and reproduction in any medium, provided the original author and source are credited. 


\section{Introduction}

Tuberculosis (TB) is one of the top 10 causes of death and the leading cause from a single infectious agent, ranking above HIV/AIDS. In 2017, there were an estimated 1.3 million TB deaths among HIVnegative people (down from 1.7 million in 2000) and an additional 3 lakh deaths among HIV-positive people. An estimated 10 million people ( $90 \%$ adults; 58\% male; 9\% people living with HIV) developed TB disease in 2017. The global incidence of tuberculosis according to Global TB Report 2017, WHO, Geneva is 10 million. India alone contributes to $27 \%$ of the total global TB burden. India forms the highest TB burden country followed by China (9\%), Indonesia (8\%), the Philippines (6\%), Pakistan (5\%), Nigeria (4\%), Bangladesh (4\%) and South Africa (3\%) [1].

The annual incidence of TB in India is 2.8 million. According to Revised National Tuberculosis Control Programme (RNTCP), 2.6 million new cases of sputum smear-positive pulmonary TB (PTB), 2 million new cases of sputum smear-negative PTB and 0.8 million new cases of extra-pulmonary tuberculosis (EPTB) were observed in 2010 worldwide (WHO, 2011). The proportion of people who develop TB and die from the disease (the case fatality ratio, or CFR) was $16 \%$ in 2016 [1-3]. Globally, use of rapid molecular tests is increasing, and many countries are phasing out the use of smear microscopy for diagnostic purposes (although microscopy and culture remain necessary for treatment monitoring).

\section{Extrapulmonary tuberculosis}

Tuberculosis that affects any organ outside the pulmonary parenchyma is designated as EPTB. Certain forms of tuberculosis occurring in sites that are fully or partially within the chest are also considered extra-pulmonary. Pleural tuberculosis and tuberculosis of the hilar or mediastinal lymph nodes are classified as extra-pulmonary (provided there are no discernible lung parenchymal abnormalities) [4]. The low yield of microscopy/ culture and the invasiveness of pleural biopsy have generated renewed interests in alternative non-invasive diagnostics [5]. Tuberculosis of the abdomen, peritoneal tuberculosis, intestinal tuberculosis, ano-rectal tuberculosis, tuberculosis of the bones and joints, tuberculosis of the spine or Pott's disease, tuberculosis of the genitourinary tract, renal tuberculosis, pericardium tuberculosis, etc. are examples of EPTB [4].
Diagnosis of EPTB, in particular, is difficult owing to paucibacillary nature of the specimens, non-uniform distribution of bacteria in these specimens as well as; the disease localized in sites that are difficult to access $[6,7]$. Smear microscopy is widely used in the diagnosis of ЕРТВ but has drawbacks owing to low and variable sensitivity values $(0-40 \%)$. Culture identification for $M$. tuberculosis also has variable sensitivities $(0-80 \%)$ in different extrapulmonary specimens with turnaround time (TAT) of 4-8 weeks and requires skilled technicians [8]. Diagnosis of EPTB from tissue samples is usually made by histo-pathological examination (HPE) does not distinguish between ЕРTB and infections from other granulomatous diseases such as sarcoidosis, leprosy and systemic lupus erythematosus (SLE). The reason for widely used PCR tests targeting IS6110 for MTBC detection is its sensitivity to detect less than 10 copies per reaction [6, 9-11].

\section{Material and methods}

This is a oneyear prospective study aimed at detecting the presence of Mycobacterial tuberculosis complex (MTBC) by MTB DNA PCR in clinically suspected cases of extra-pulmonary tuberculosis and also comparing the results with conventional Ziehl-Neelsen stained smears. The study was conducted in the Department of Microbiology and Molecular biology at Krishna Institute of Medical Sciences Limited, Secunderabad. Various samples (CSF, Fluids, Tissue, Urine, etc.) from patients suspected of having EPTB; received for PCR during the period from March 2017 to February 2018 were included in the study. Samples received were processed according to standard microbiological guidelines. Smears were prepared from the samples and subjected to Ziehl-Neelsen (ZN) staining for detection of acid fast bacilli (AFB).

The DNA PCR was performed by using 3B BIOTUB KIT (3B BlackBio Biotech India Ltd) for qualitative detection of Mycobacterium tuberculosis. The process is a two-step amplification reaction. The first reaction uses a pair of primers (5X MTB PM-1) which hybridizes with conserved sequences specific to $M$. tuberculosis i.e. IS6110 region. The second reaction is a nested amplification reaction which uses the product from the first amplification reaction as template, and a pair of primers (4X MTB PM-2). The samples received for MTB DNA PCR were processed according to manufacturer's instructions [9]. 
After initial processing of each specimen; DNA extraction was done using Qiagen QIAcube Robotic workstation (Figure 1) which is a fully automated processing system for sample purification and DNA extraction. The instrument controls integrated components including a centrifuge, heated shaker, pipetting system, and robotic gripper.

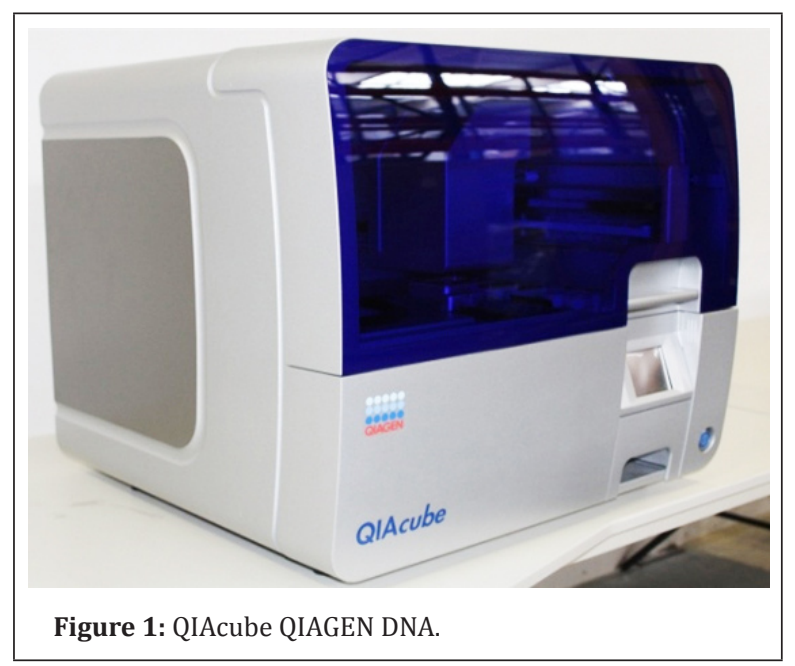

The QIAcube is preinstalled with various protocols for processing QIAGEN spin columns for purification of RNA, genomic DNA, plasmid DNA, viral nucleic acids, or proteins, plus DNA and RNA cleanup. Sample preparation using the QIAcube follows the same steps as the manual procedure (i.e., lyse, bind, wash, and elute).

Next step; amplification of DNA is performed as nested PCR reaction. PCR master mix is prepared for first reaction and using eppendorf thermocycler (Figure 2) and the reaction is run for 30 cycles followed by preparation of PCR mix for nested PCR reaction and run for 35 cycles.



In final step, the analysis of amplification products was performed by using ethidium bromide instilled agarose (1.5-2\%) gel electrophoresis. $10 \mu \mathrm{l}$ of PCR products and $10 \mu \mathrm{l}$ of BIOTUB Marker were electrophoresed at $150 \mathrm{~V}$ in TAE $1 \mathrm{X}$ tank buffer for $30 \mathrm{~min}$ or till dye front reached $3 / 4^{\text {th }}$ of the gel. The results were interpreted based on presence or absence of internal control (IC) band (BIOTUB Marker) and MTB band (PCR product size) (Figure 3).



Figure 3: Gel electrophoresis bands in MTB DNA PCR.

\section{Results}

A total of 156 samples from suspected cases of extrapulmonary tuberculosis patients were received for MTB PCR. Out of total 156 enrolled patients, 100 were in-patient samples and 56 out-patient samples. The various clinical samples received includes - CSF (86), Endometrial tissue (29), Urine (15), Intestinal tissue (11), Pleural fluid (7), other tissues (5) [lymph node biopsy tissue -2 , abdominal tissue -1 , breast tissue -1 , peritoneal tissue -1] and other fluid (3) [ascitic fluid - 1, pericardial fluid - 1, synovial fluid - 1] (Table 1).

Table 1: List of clinical samples received for MTB DNA PCR.

\begin{tabular}{|llc|}
\hline S. No. & Clinical samples & No. of samples \\
\hline 1 & CSF & 86 \\
2 & Endometrial tissue & 29 \\
3 & Urine & 15 \\
4 & Intestinal tissue & 11 \\
5 & Pleural fluid & 7 \\
6 & Others & 8 \\
Total samples & 156 \\
\hline
\end{tabular}


All 156 samples received, were negative for acid fast bacilli (AFB) by ZN staining. Out of total 156 samples received; $8(5.12 \%)$ samples were detected positive by MTB-DNA PCR test. The positive results were seen in CSF-4, urine-2, pleural fluid-1 \& endometrial tissue-1 (Figure 4).



Gender predominance of extra-pulmonary tuberculosis was seen in males (Figure 5) \& cases of EPTB were distributed in all age-groups (Figure 6).
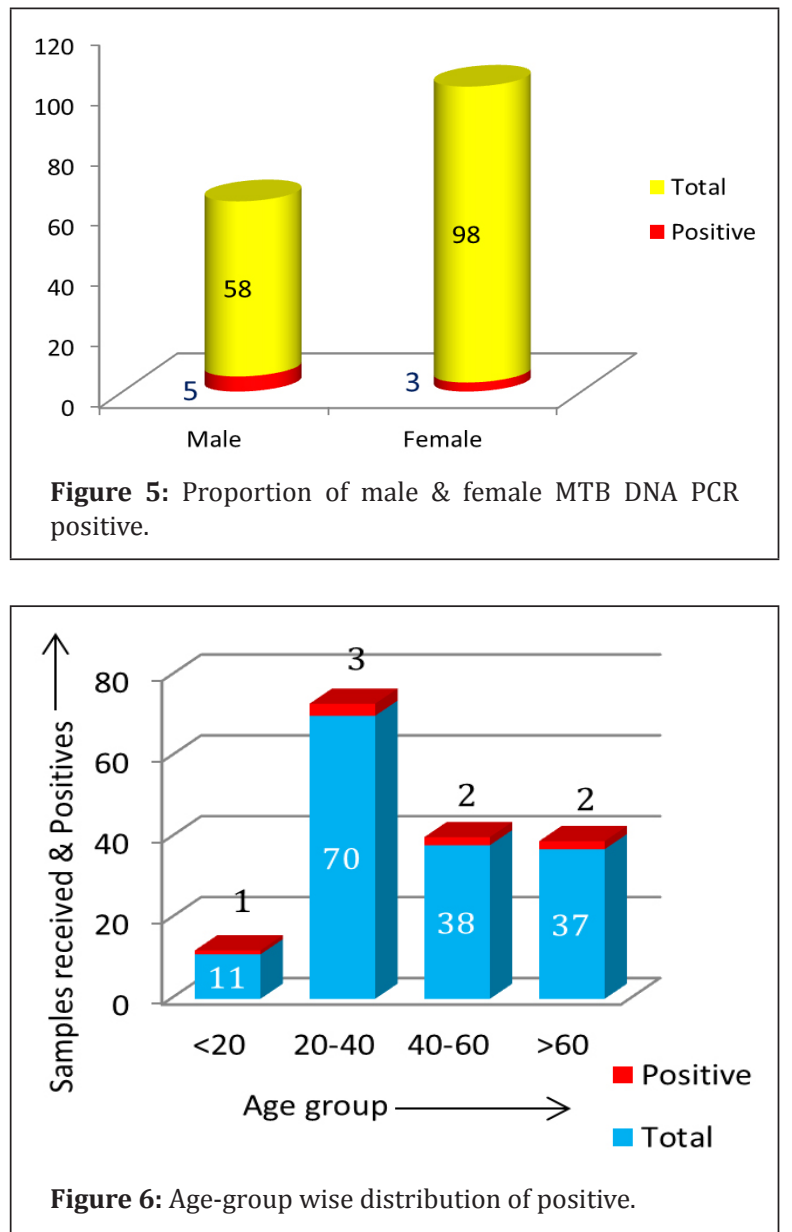

In this study most common site of extra-pulmonary tuberculosis was pleura (14.28\%), followed by genito-urinary tuberculosis (13.33\%), Central Nervous System (CNS) related tuberculosis (4.65\%) and endometrial tuberculosis (3.44\%) in the descending order, respectively (Figure 7 \& 8).



Figure 7: Sites of EPTB cases.



\section{Discussions}

India contributes to the highest TB disease burden in the world according to recent WHO TB burden report 2018 [1]. The mortality and morbidity due to the tuberculosis disease is high; though showing $1-2 \%$ decrease every year with the National TB control program [3]. This scenario demands the need of rapid and accurate diagnosis, in order to start early treatment and reduce the mortality and morbidity associated with the disease per se.

With high burden of tuberculosis, there is also increasing trend in extra-pulmonary tuberculosis 
cases. The incidence of EPTB ranges from $12 \%$ to $52 \%$ worldwide. The paucibacillary nature of EPTB owes to the difficulty in diagnosis. Being a treatable disease, early diagnosis is of utmost importance to reduce the morbidity \& mortality caused by EPTB. In today's advancing era of diagnosis, conventional culture still remains the gold standard. Though the turnaround time (TAT) being 6-8 weeks is a major drawback. In case of EPTB, the sensitivity of AFB detection by ZN staining of direct smears is extremely low $[6,10,11]$.

MTB DNA PCR method plays an important role in detection of M. tuberculosis results within few hours whereas conventional culture method takes days to weeks. The sensitivity of detection of MTB by using 3B BIOTUB Kit for DNA PCR is that it can detect less than 10 copy numbers per reaction [9]. This makes PCR a sensitive and a rapid method for diagnostic purpose. One of the demerits of this test is that it could not differentiate between viable and dead bacilli. Also few studies from different geographical regions of the world have reported that some clinical isolates have either a single copy or no copy of IS6110 that leading to false-negative results. This can be overcome by using mRNA-based RT-PCR; which can detect viable $M$. tuberculosis bacilli and is useful for the diagnosis of active disease. However, the sensitivity of the assay is low and it is cumbersome to work with RNA in routine use $[8,12,13]$.

In this one year study, while all samples were negative for AFB by ZN staining method, the MTBC was found positive in 8 cases out of total 156 cases by MTB DNA nested PCR method. Most common site of EPTB detected in the study was pleura followed by genito-urinary tract which is similar to findings in study conducted by Gaur et al., Chander et al and Ravikumar et al. [14-16]. In this study ЕРTB was seen predominantly in males similar to study conducted by Ravikumar et al. [16]. In contrast to study conducted by Gaur et al. where in female preponderance of EPTB was seen [14].

With the recent advances in diagnostic methods, PCR forms a convenient method for MTB detection in short duration. The reason for widely used IS6110 in PCR tests is the presence of its multiple copies in M. tuberculosis complex genome, which is believed to confer higher sensitivity $[17,18]$. So owing to paucibacillary nature and uneven distribution of bacilli in EPTB samples, PCR plays a sensitive role. It also reduces the TAT to a great extent which provides opportunity for early diagnosis and treatment of EPTB. This in turn improves the quality of life of patients suffering from the disease.

In cases of diagnostic dilemma, where AFB smear comes negative and while waiting for culture results; PCR can aid in early therapeutic decision making. Other recent studies also confirmed PCR to be a rapid and sensitive method for diagnosing EPTB compared to conventional microbiologic methods $[6-8,10,11]$. Clinical correlation and other lab findings are important and should be considered along with PCR.

\section{Conclusion}

Early diagnosis and treatment of EPTB reduces the complications and morbidity in patients. Though PCR is expensive, where-ever feasible and whenever in diagnostic dilemma in cases of EPTB, it can be included in diagnostic panel to clinch the diagnosis early and aid in starting of pre-emptive treatment while culture results are awaited. In conjunction with other conventional methods, along with clinical findings and radio-pathological correlation, PCR forms an important diagnostic tool.

\section{Limitations of study}

The test could not differentiate between viable and dead bacilli. So this test cannot be use for monitoring treatment efficacy or patient prognosis. Negative results should not dissuade the clinician from empirically treating EPTB patients in the background of high clinical suspicion.

\section{Acknowledgement}

The whole team of Department of Microbiology, Department of Molecular Biology and Laboratory Medicine, Krishna Institute of Medical Sciences Limited for giving the opportunity, help and directions to perform this study.

\section{Conflicts of interest}

Authors declare no conflicts of interest.

\section{References}

[1] WHO. Global Tuberculosis. 2018; 1-265 p.

[2] WHO. Global Tuberculosis. 2017; 1-227 p.

[3] Programme RNTCP. India TB Report. 2018; 1-156. 
[4] Ait-Khaled N, Enarson DA. Tuberculosis a manual for medical students. WHO. 2003; p:1-148.

[5] Light RW. Update on tuberculous pleural effusion. Respirology. 2010; 15(3):451-458.

[6] Raveendran R, Wattal C. Utility of multiplex real-time PCR in the diagnosis of extrapulmonary tuberculosis. Brazilian J Infect Dis. 2016; 20(3):235-241.

[7] Chakravorty S, Sen MK, Tyagi JS. Diagnosis of extrapulmonary tuberculosis by smear, culture, and PCR using universal sample processing technology diagnosis of extrapulmonary tuberculosis by smear, culture, and PCR using universal sample processing technology. J Clin Microbiol. 2005; 43(9):4357-4362.

[8] Mehta PK, Raj A, Singh N, Khuller GK. Diagnosis of extrapulmonary tuberculosis by PCR. FEMS Immunol Med Microbiol. 2012; 66(1):20-36.

[9] Kit BQT, Kit BQT, Kit BQT. 3B BIOTUB ® QT Kit:0-25.

[10] Khosravi AD, Alami A, Meghdadi H, Hosseini AA. Identification of Mycobacterium tuberculosis in clinical specimens of patients suspected of having extrapulmonary tuberculosis by application of nested PCR on five different genes. Front Cell Infect Microbiol. 2017; 7:3.

[11] Travelers' Health. Chapter 3 - Infectious diseases related to travel. Centers for disease control and prevention. 2017. Available from: https://wwwnc.cdc.gov/travel/ yellowbook/2018/infectious-diseases-related-to-travel/ tuberculosis

[12] Rana T, Singh UB, Kulshrestha V, Kaushik A, Porwal C, et al. Utility of reverse transcriptase PCR and DNA-PCR in the diagnosis of female genital tuberculosis. J Med Microbiol. 2011; 60(Pt 4):486-491.

[13] Causse M, Ruiz P, Gutierrez-Aroca JB, Casal M. Comparison of two molecular methods for rapid diagnosis of extrapulmonary tuberculosis. 2011; 49(8):3065-3067.

[14] Gaur PS, Suryakant, Bhaskar R, Singh S, Saxena P, et al. Incidence and clinical profiles of pulmonary and extrapulmonary tuberculosis patients in north Indian population: A hospital based retrospective study. Int J Res Dev Pharm L Sci. 2017; 6(5):2773-2778.

[15] Chander V, Raina SK, Bhardwaj AK, Kashyap S, Gupta AK, et al. Clinico-epidemiological profile of extra pulmonary tuberculosis: A report from a high prevalence state of northern India. Pub H Res. 2012; 2(6):185-189.

[16] Ravikumar P, Bai PG. A study of extra-pulmonary tuberculosis and its outcome. Int J Adv Med. 2017; 4(1):209-213.

[17] Jin XJ, Kim JM, Kim HK, Kim L, Choi SJ, et al. Histopathology and TB PCR kit analysis in differentiating the diagnosis of intestinal tuberculosis and Crohn's disease. World J Gastroenterol. 2010; 16(20):2496-2503.

[18] Rafi W, Venkataswamy MM, Ravi V, Chandramuki A. Rapid diagnosis of tuberculous meningitis: a comparative evaluation of in-house PCR assays involving three mycobacterial DNA sequences, IS6110, MPB-64 and $65 \mathrm{kDa}$ antigen. J Neurol Sci. 2007; 252(2):163-168. 